\title{
Sclerotinia sclerotiorum Populations Infecting Canola from China and the United States Are Genetically and Phenotypically Distinct
}

\author{
Renuka N. Attanayake, Patrick A. Carter, Daohong Jiang, Luis del Río-Mendoza, and Weidong Chen
}

First author: Department of Plant Pathology, and second author: School of Biological Sciences, Washington State University, Pullman 99164; third author: Department of Plant Protection, Huazhong Agricultural University, Wuhan, Hubei, People's Republic of China; fourth author: Department of Plant Pathology, North Dakota State University, Fargo 58108; and fifth author: United States Department of Agriculture-Agricultural Research Service, Washington State University, Pullman 99164.

Accepted for publication 25 February 2013.

\begin{abstract}
Attanayake, R. N., Carter, P. A., Jiang, D., del Río-Mendoza, L., and Chen, W. 2013. Sclerotinia sclerotiorum populations infecting canola from China and the United States are genetically and phenotypically distinct. Phytopathology 103:750-761.

Genetic and phenotypic diversity and population differentiation of Sclerotinia sclerotiorum isolates infecting canola from China and the United States were investigated. Genetic diversity was assessed with eight microsatellite markers and mycelial compatibility groups (MCGs). Phenotypic diversity was assessed with sensitivity to three fungicides, production of oxalate and sclerotia, growth rate, and virulence on two canola cultivars. No shared MCGs or multilocus haplotypes were detected between the two populations, and populations differed significantly

$(P<0.001)$. Recombination was detected in both populations but was greater in the Chinese population. A polymerase chain reaction detection assay showed that $\sim 60 \%$ of the isolates were inversion-plus at the mating type locus. The two populations differed significantly $(P<0.05)$ for all of the phenotypic traits except for sensitivity to fungicide fluazinam and virulence. Isolates in the Chinese population were unique in several aspects. Despite the phenotypic differentiation, heritabilities of the phenotypic traits were similar for both populations. Significant correlations were found among five phenotypic traits. Cross resistance to benomyl and iprodione was detected. Virulence was not significantly correlated with any other phenotypic trait and had the least heritability. However, both populations were equally virulent on either a susceptible or a moderately resistant canola cultivars.
\end{abstract}

Sclerotinia sclerotiorum is a cosmopolitan fungal plant pathogen which causes white mold on $>400$ plant species, including canola, around the world (6). S. sclerotiorum employs a diverse array of mechanisms in causing disease on a wide variety of hosts. Early pathogenicity events involve synergistic interactions between oxalic acid production and secretion of cell-walldegrading enzymes, lowering the ambient $\mathrm{pH}$ of the infected tissues and compromising plant defense responses $(13,27)$. Once the disease is established, the pathogen produces the survival structure, sclerotia, inside the pith or on plant tissues that can fall to the soil during harvesting or other disturbances and can survive in soil for up to 8 years (25). When conditions are favorable for the pathogen, myceliogenic or carpogenic germination of sclerotia initiates another disease cycle.

Currently, no canola cultivars have complete resistance to Sclerotinia white mold, and fungicide application and cultural practices are important in controlling the disease (7). Historically, benomyl had been applied to control white mold in canola in China (35) and Canada (24). Resistance to benomyl can develop due to point mutations of the $\beta$-tubulin gene in $S$. sclerotiorum (35) as well as in other fungi (32). A laborious plate assay with a series of fungicide concentration gradients has been used to identify resistant isolates, and sequencing the $\beta$-tubulin gene is required to confirm benomyl-resistant genotypes (32). Currently, azoxystrobin, boscalid, thiophanate-methyl, and vinclozolin are registered for controlling Sclerotinia stem rot on canola in the

Corresponding author: W. Chen; E-mail: w-chen@wsu.edu

http://dx.doi.org/10.1094/PHYTO-07-12-0159-R

This article is in the public domain and not copyrightable. It may be freely reprinted with customary crediting of the source. The American Phytopathological Society, 2013.
United States (7). Iprodione is recommended on canola in Canada (7) and in China (37), and its potential use within the United States has been discussed (7). Therefore, fungicide resistance, production of oxalic acid and sclerotia, growth rate, and virulence are important phenotypic traits of $S$. sclerotiorum. In a previous study, Atallah et al. (3) detected no variation in aggressiveness and in response to fungicides among isolates of S. sclerotiorum from potato in the Columbia Basin, Washington State (3). Durman et al. (12) found significant differences in oxalate production among isolates collected from different hosts from Argentina. Several other studies have reported variation in mycelial compatibility groups (MCGs) and pathogenicity among isolates from Iran (31), Argentina and the United States (34), and China, Canada, and England (36). However, a detailed phenotypic characterization and potential relationships among the phenotypic traits have not been studied, especially between geographically isolated populations.

Population genetic structure and differentiation of this ubiquitous plant pathogen has been a subject of numerous studies. Early studies found widespread distribution of a few MCGs or haplotypes over time and space and concluded that $S$. sclerotiorum has a clonal population structure $(2,26,33)$. However, most recent studies using robust molecular markers such as microsatellites have found recombining as well as clonal population structures in $S$. sclerotiorum worldwide $(3,23,28,40,51)$. Atallah et al. (3) reported recombining populations and a lack of population differentiation among four populations of $S$. sclerotiorum from potato fields in the Columbia Basin in Washington State of the United States. Hemmati et al. (28) found only one large panmictic population among 276 isolates from 37 canola fields in Iran, and evidence of outcrossing was found in all field populations. Similarly, one large genetic population was found among 250 isolates collected from two sunflower fields in Australia and 
recombination was detected (16). In contrast, population differentiation of $S$. sclerotiorum was reported in a number of studies. Gomes et al. (23) reported a population differentiation and high number of private alleles among $S$. sclerotiorum populations from irrigated bean fields in Brazil. Sexton et al. (50) reported genetic differentiation among $S$. sclerotiorum populations from canola fields in Australia. Malvárez et al. (38) reported three genetically differentiated populations from various crops in California and Washington in the United States and Ontario in Canada. These studies were conducted on a local or regional scale of isolates and focused mainly on genetic structure, and few phenotypic characteristics were examined in relation to genotypic variation. A more comprehensive study of genetic diversity, population differentiation, and phenotypic traits relevant to agricultural practices on the same set of isolates will provide us a better understanding of S. sclerotiorum.

According to Fisher's fundamental theorem of natural selection, in a challenging environment with frequent fluctuations (e.g., an agricultural ecosystem with frequent application of pesticides, crop rotation, and short cropping cycles), populations with less genetic variation for fitness traits may be vulnerable for extinction (39). Populations with high genetic variation can readily adapt to adverse environments (57). Conversely, a highly adapted population may have low genetic variance for the adapted traits because of the erosion of genetic variance that occurs under selection (22). This relationship can be shown as $R=h^{2} S$, where $R$ is the response to selection, $h^{2}$ is heritability, and $S$ is selection differential (22). Because heritability is a measure of the proportion of phenotypic variation that is due to genetic variance, selection over time reduces genetic variance and, hence, heritability. Conversely, phenotypic traits with high heritability can readily respond to selection. Thus, knowledge of heritability of a pathogen can help in devising disease control measures. For example, high heritability of response to a fungicide suggests a high likelihood of developing resistance to said fungicide. Heritability is estimated using variance components and the relationship can be shown as $h^{2}=V_{\mathrm{A}} / V_{\mathrm{P}}$, where, $V_{\mathrm{A}}$ is the additive genetic variance and $V_{\mathrm{P}}$ is the total variance $\left(V_{\mathrm{P}}=V_{\mathrm{A}}+\right.$ environmental variance $\left.\left[V_{\mathrm{E}}\right]\right)$. To our knowledge, genetic variance and heritability of phenotypic traits of $S$. sclerotiorum have not been studied before. Geographically distant populations with restricted gene flow evolve separately and result in population differentiation. Specific ecologically beneficial characteristics (morphological, physiological, or genetic) may be selected in different geographical locations, resulting in populations undergoing adaptive differentiations. Therefore, geographically isolated populations may display genetic and phenotypic differentiation due to differential selection resulting from environmental variation and differences in crop rotation and control practices over time.

Understanding genetic diversity of agronomically important traits and population differentiation are important in developing and applying disease management strategies and understanding the pathogen's ability to respond the management practices. Populations of $S$. sclerotiorum infecting canola from China and the United States were compared for genetic and phenotypic diversity using microsatellite markers and agronomically important quantitative traits: fungicide sensitivity, oxalic acid production, sclerotial dry weight, growth rate, and virulence. The choice of geographically isolated populations allowed us to test the hypothesis that geographically distant populations with distinct environmental conditions would display significant genetic and phenotypic differentiation. The first objective of this research was to study the population genetic structure, genetic diversity, and population differentiation of geographically distant populations under discrete environmental conditions. The second objective was to assess whether the populations differ in genetic variance and heritability of each phenotypic trait and infer potential response of the populations to selection.

\section{MATERIALS AND METHODS}

Sample collection and DNA isolation. Sclerotia of S. sclerotiorum were obtained from infected plants from commercial canola fields in China and the United States: 29 from North Dakota in 2009, and 30 from Tongcheng County, Anhui province, China in 2010 (Table 1). Sclerotia were collected from plants that were at least $6 \mathrm{~m}$ apart to ensure that isolates were from different infection foci, even though it is common to have multiple genotypes infecting single canola plants $(50,51)$. Sclerotia were surface sterilized (1 min each in 70\% ethanol and 3\% sodium hypochlorite), rinsed three times with sterile distilled water, aseptically cut into halves, and plated on potato dextrose agar (PDA) (Difco Laboratories, Detroit). One isolate was obtained from each sclerotium and kept at $4^{\circ} \mathrm{C}$ for short-term storage. Total genomic DNA was isolated from 10 to 15 sclerotia of each isolate using a FastDNA SPIN Kit (MP Biomedicals, Solon, OH) following the manufacturer's instructions with minor modifications.

Microsatellite genotyping. Eight microsatellite loci developed by Sirjusingh and Kohn (52) were used to investigate the genetic diversity. Polymerase chain reaction (PCR) reactions were performed with one of the four fluorophores (Vic, Pet, Ned, and Fam), multiplexed, and genotyped using an ABI3730xl DNA Analyzer (Applied Biosystems, Foster City, CA) at the United States Department of Agriculture-Agricultural Research Service Western Regional Small Grain Genotyping Laboratory, Pullman, WA. GeneMarker software (SoftGenetics, LLC State College, PA) was used for the fragment analysis. PCR conditions were similar to those described by Sirjusingh and Kohn (52). Each isolate was genotyped at least twice for each locus.

Statistical analysis of microsatellite data. Population genetic parameters for genetic diversity-number of polymorphic loci, mean number of alleles per locus (allelic richness), expected heterozygosity (42), and the number of private alleles (those found only in one population) in each population-were estimated using programs GenAIEx 6 (45) and Arlequin ver. 3.5 (19). Allele frequencies were compared between the populations. Multilocus genotypic diversity was estimated using several methods: number of unique haplotypes observed in each population $(g)$, Stoddart and Taylor's $G(54)$, and genotypic richness $(g / N)$.

Bayesian clustering of the isolates to determine the most probable number of genetic clusters without considering geographic origins was carried out using the program Structure ver. 2.2 (48), and the admixture model (individuals are allowed to have ancestry from multiple populations) was used. Five independent runs were conducted to assess the consistency between the runs for each $k$ value, with 100,000 Markov Chain Monte-Carlo iterations followed by a burning period of 500,000 iterations. The most probable number of genetically homogenous clusters $(k)$ was estimated as described by Evanno et al. (18) using software Structure Harvester ver. 0.6 (14). A principle coordinate analysis (PCoA) was performed using GenAlEx to test the population clustering using microsatellite data. PCoA has an advantage over the Structure due to lack of strong assumptions of underlying genetic models such as linkage equilibrium.

The level of population differentiation was evaluated using analysis of molecular variance (AMOVA). AMOVA uses an analysis of variance (ANOVA) framework to partition the total variance into covariance components due to between- and withinpopulation differences (21). Variances were computed with a matrix of squared genetic distances between all pairs of haplotypes using the step-wise mutation model (53). The null hypothesis of AMOVA, that $S$. sclerotiorum isolates from China and the United States were not genetically differentiated, was tested with 1,023 permutations by a nonparametric approach implemented in Arlequin.

Evolutionary relationships among haplotypes were graphically represented using a minimum spanning network (MSN) (20) ob- 
tained from a pairwise distance matrix, assuming the stepwise mutation model (53) as implemented in Arlequin. HapStar ver. 0.5 (55) and Inkscape ver. 0.48 (http://www.inkscape.org) were employed to visualize and edit the MSN.

TABLE 1. Sclerotinia sclerotiorum isolates from China (prefixed with C) and the United States (prefixed with $\mathrm{U}$ ) and their mycelial compatibility group (MCG), mating type idiomorphs detected with PCR, $\beta$-tubulin gene sequence type, and colony color

\begin{tabular}{|c|c|c|c|c|}
\hline Isolate $^{\mathrm{a}}$ & MCG & $M A T^{\mathrm{b}}$ & Sequence type ${ }^{c}$ & Colony color ${ }^{\mathrm{d}}$ \\
\hline $\mathrm{C} 01$ & 1 & 2 & III & Beige \\
\hline $\mathrm{C} 02$ & 2 & $1 \& 2$ & II & Beige \\
\hline $\mathrm{C} 03$ & 3 & $1 \& 2$ & II & Beige \\
\hline $\mathrm{C} 04$ & 4 & $1 \& 2$ & II & Beige \\
\hline $\mathrm{C} 05$ & 5 & 2 & II & Beige \\
\hline $\mathrm{C} 06$ & 6 & 2 & II & Black \\
\hline $\mathrm{C} 07$ & 7 & $1 \& 2$ & II & Black \\
\hline $\mathrm{C} 08$ & 8 & 2 & III & Beige \\
\hline $\mathrm{C} 09$ & 9 & 2 & III & Black \\
\hline $\mathrm{C} 10$ & 10 & 2 & III & Black \\
\hline $\mathrm{C} 11$ & 11 & 2 & III & Beige \\
\hline $\mathrm{C} 12^{*}$ & 7 & $1 \& 2$ & III & Black \\
\hline $\mathrm{C} 13$ & 12 & $1 \& 2$ & III & Black \\
\hline $\mathrm{C} 14$ & 13 & 2 & III & Black \\
\hline $\mathrm{C} 15$ & 14 & 2 & IV & Beige \\
\hline $\mathrm{C} 16$ & 15 & $1 \& 2$ & III & Beige \\
\hline $\mathrm{C} 17$ & 16 & $1 \& 2$ & II & Beige \\
\hline C18* & 7 & 2 & II & Beige \\
\hline C19 & 17 & $1 \& 2$ & III & Beige \\
\hline $\mathrm{C} 20$ & 8 & 2 & III & Black \\
\hline $\mathrm{C} 21$ & 18 & 2 & III & Black \\
\hline $\mathrm{C} 22$ & 19 & 2 & II & Beige \\
\hline $\mathrm{C} 23$ & 21 & 2 & II & Black \\
\hline C24* & 26 & $1 \& 2$ & IV & Beige \\
\hline $\mathrm{C} 25$ & 20 & 2 & II & Black \\
\hline $\mathrm{C} 26$ & 22 & $1 \& 2$ & II & Black \\
\hline $\mathrm{C} 27$ & 23 & $1 \& 2$ & II & Black \\
\hline $\mathrm{C} 28$ & 24 & 2 & II & Black \\
\hline C29 & 25 & 2 & II & Black \\
\hline C30 & 27 & $1 \& 2$ & III & Beige \\
\hline U01 & 28 & $1 \& 2$ & III & Beige \\
\hline U02 & 29 & 2 & I & Beige \\
\hline U03 & 30 & 2 & III & Beige \\
\hline U04 & 31 & 2 & I & Beige \\
\hline U05 & 32 & $1 \& 2$ & I & White \\
\hline U06 & 33 & 2 & I & Beige \\
\hline U07* & 34 & 2 & I & Beige \\
\hline U08 & 35 & $1 \& 2$ & I & White \\
\hline U09 & 36 & 2 & I & Beige \\
\hline U10 & 37 & 2 & I & Beige \\
\hline U11 & 38 & $1 \& 2$ & I & Beige \\
\hline U12 & 39 & 2 & I & Beige \\
\hline U13 & 35 & $1 \& 2$ & I & Beige \\
\hline U14 & 40 & $1 \& 2$ & III & Beige \\
\hline U15 & 41 & 2 & I & Beige \\
\hline U16 & 41 & 2 & I & Beige \\
\hline U17 & 42 & 2 & I & Beige \\
\hline U18 & 42 & 2 & I & Beige \\
\hline U19 & 42 & 2 & III & Beige \\
\hline U20 & 36 & 2 & I & Beige \\
\hline U21 & 36 & 2 & I & Beige \\
\hline U22 & 36 & $1 \& 2$ & I & Beige \\
\hline U23 & 35 & $1 \& 2$ & I & Beige \\
\hline $\mathrm{U} 24$ & 43 & $1 \& 2$ & I & Beige \\
\hline U25 & 43 & $1 \& 2$ & I & Beige \\
\hline U26 & 44 & $1 \& 2$ & III & Beige \\
\hline U27 & 35 & 2 & I & Beige \\
\hline U28 & 45 & $1 \& 2$ & I & White \\
\hline U29 & 46 & 2 & I & White \\
\hline
\end{tabular}

${ }^{a}$ An asterisk (*) indicates isolate deposited at the Washington State University herbarium and its $\beta$-tubulin gene sequence deposited at GenBank.

b Symbols: 2 refers to detection of MAT1-2 idiomorph only, as shown in Figure 2 (inversion-plus isolates), and $1 \& 2$ refers to detection of both MAT1-1 and MAT1-2 idiomorphs (inversion-minus isolates).

${ }^{\mathrm{c}}$ Sequence type refers to $\beta$-tubulin gene sequence types presented in Figure 3.

${ }^{\mathrm{d}}$ Colony colors were illustrated in Figure 6.
Linkage disequilibrium indices, index of association $\left(I_{A}\right)$, and a modified statistic $\left(r_{d}\right)$ without dependency on number of loci examined were estimated with Multilocus ver. 1.3 software (1). Briefly, the observed variance of distances (estimated by the number of different loci) between all pairs of individuals was compared with the expected variance of a simulated data set having unlimited recombination. The variance of distances of a recombining population is normally distributed whereas the variance of distances of a clonal population is skewed. The statistical significance of observed values were tested against the null hypothesis of random mating with 1,000 randomizations of the data set.

Mycelial compatibility grouping. MCGs were determined by pairing isolates in all possible combinations on PDA plates amended with red food coloring (49). Actively growing mycelial discs $(6 \mathrm{~mm}$ in diameter) were placed $2 \mathrm{~cm}$ apart in a 9-cmdiameter petri plate and incubated at room temperature (23 to $25^{\circ} \mathrm{C}$ ) in the dark for 1 week. Self-pairing was included as a control in every plate. The presence of an antagonistic barrage zone at the contact points was recognized as an incompatible reaction and a compatible reaction was characterized as merging colonies and formation of a confluent uniform colony. Compatible isolates were grouped into one MCG and incompatible isolates were placed in different MCGs. Each pair was tested at least twice.

PCR detection of MAT loci. A PCR screening was performed to determine whether all of the isolates harbor complete sequences of both of the MAT idiomorphs. The MAT1-1 $\alpha$ and MAT1-2 HMG idiomorphs are at a single MAT locus in the genomic sequence of $S$. sclerotiorum strain 1980 (38). Primers flanking a 673-bp region in the MAT1-1 $\alpha$ and a 650-bp MAT1-2 HMG box were used to detect the presence of MAT1-1 and MAT1-2 under PCR conditions described by Malvárez et al. (38). When no PCR product was amplified, other different PCR conditions were attempted. Chitrampalam et al. (10) demonstrated that the mating type gene goes through inversion each time it undergoes meiosis. Inversion-minus isolates show PCR products of both mating type idiomorphs, whereas inversion-plus isolates show the PCR product of only the MAT1-2 idiomorph due to truncation of the MAT1-1 gene by inversion (10).

$\beta$-Tubulin gene sequencing. In order to confirm benomyl resistance phenotype of some isolates, a partial $\beta$-tubulin gene was amplified using primers TubF (5'-AAATCACCCACTCT CTCG- $3^{\prime}$ ) and TubR (5'-CTCCATCTCGTCCATACC-3'). These primers were modified from $\mathrm{Li}$ et al. (35) by replacing the degenerate nucleotides in the primers B1 and B3 with the nucleotides of $\beta$-tubulin gene sequence in the $S$. sclerotiorum genome database (http://www.broadinstitute.org/annotation/genome/ sclerotinia_sclerotiorum/MultiHome.html). PCR products of all 59 isolates were sequenced at Elim Biopharm Inc., Hayward, CA. in both directions and sequences were manually edited, aligned, and compared with the sequence of the $\beta$-tubulin gene in the genome database (SS1G_04652) of S. sclerotiorum using BioEdit ver. 7.1.3 (Tom Hall Ibis Biosciences, Carlsbad, CA). Singlenucleotide polymorphisms (SNPs) and amino acid substitutions were searched and the $\beta$-tubulin gene sequence types were compared with the phenotypes of benomyl sensitivity in a fungicide sensitivity assay, as described below.

Fungicide sensitivity. All the experiments for phenotypic diversity estimations were designed as a completely randomized design. Sensitivities of all the isolates to three different fungicides were evaluated. Technical-grade fungicides iprodione (BASF, Research Triangle Park, NC) and fluazinam (Syngenta Crop Protection Inc., Greensboro, NC) were used. Formulated product of benomyl (benlate 50WP, 50\% a.i.; DuPont Agricultural products, Wilmington, DE) was used because technical-grade benomyl was not available. Single discriminatory concentrations, which gave the highest variance in growth rates of $S$. sclerotiorum isolates determined in a previous study (4), were used for benomyl $(0.2 \mu \mathrm{g}$ 
a.i/ml), fluazinam $(0.005 \mu \mathrm{g} \mathrm{a.i} / \mathrm{ml})$, and iprodione $(0.25 \mu \mathrm{g}$ a.i $/ \mathrm{ml})$ in sensitivity tests. Fungicide-amended PDA plates were inoculated with 5-mm agar disks from the edge of actively growing colonies and incubated in the dark at room temperature (23 to $25^{\circ} \mathrm{C}$ ). Colony diameters on control PDA plates without fungicides and on PDA plates amended with fungicide were measured $36 \mathrm{~h}$ after inoculation. Percent inhibition $(I)$ was calculated using the formula $I=[(C-F) / C] \times 100$, where $C$ is colony diameter on the control plate and $F$ is colony diameter on the fungicideamended plate. Each isolate was tested on three replicate plates and the experiment was repeated once.

Oxalic acid production and growth rate. Production of oxalic acid in potato dextrose broth (PDB) was quantified by reversephase high-performance liquid chromatography (HPLC). PDB ( $25 \mathrm{ml}$ ) (Difco Laboratories) in 125-ml flasks was inoculated with three 5-mm actively growing mycelial disks from PDA. Three replicate flasks were prepared for each isolate. Control flasks were inoculated with plain PDA plugs. Cultures were statically incubated for 4 days at room temperature $\left(23\right.$ to $\left.25^{\circ} \mathrm{C}\right)$ with a 12-h photoperiod. Mycelium was removed by vacuum filtration through Whatman number 1 filter paper, and mycelial dry weight was determined after drying at $65^{\circ} \mathrm{C}$ for 3 days and used as a measure of growth rate. Culture filtrates were filtered through $0.45-\mu \mathrm{m}$ membrane filters and used in HPLC analysis. The amount of oxalate present in $10 \mu \mathrm{l}$ of the sample was separated and determined using HPLC with a standard curve constructed with oxalic acid anhydrate (Sigma-Aldrich, St. Louis). HPLC was performed using an Eclipse XDB-C18 (4.6 by $250 \mathrm{~mm}, 5 \mu \mathrm{m}$ column, Agilent Technologies, Waldbronn, Germany) and oxalate was detected with UV light at $210 \mathrm{~nm}$, as previously described (4). The amount of oxalic acid produced by each isolate was expressed as total oxalate per flask and per unit dry weight of mycelia (oxalate $\mathrm{mg} / \mathrm{mg}$ ). The experiment was repeated once.

Colony color and sclerotial production. Mycelial plugs ( $5 \mathrm{~mm}$ in diameter) from the edge of actively growing colonies on PDA were transferred into the center of PDA (Difco Laboratories) plates $(20 \mathrm{ml}$ per plate, three plates per isolate). Plates were incubated with a 12 -h photoperiod at room temperature (23 to $25^{\circ} \mathrm{C}$ ) for 2 weeks, then placed in the dark for another week before recording the colony color. Colony colors were visually evaluated and recorded as white, beige, or black, as previously described (4). The plates were then incubated in the dark at room temperature for 2 months before harvesting sclerotia. Sclerotia were dried under vacuum for 3 days and dry weight per plate was measured. Each isolate was replicated three times and the experiment was performed twice.

Virulence assay. A detached-leaf assay was conducted in moist chambers prepared by placing a filter paper moistened with $4 \mathrm{ml}$ of sterilized distilled water in a petri dish $(15 \mathrm{~cm}$ in diameter). Fully expanded youngest leaves of 6-week-old 'Dekalb 30-42' (susceptible) and 'Hyola 357 Magnum' (moderately resistant) canola were used in the virulence assay. Fungal cultures were grown on V8 juice agar (20\% V8 juice, $0.3 \% \mathrm{CaCO}_{3}, 80 \%$ deionized water, and $2 \%$ Bacto agar). A 5-mm-diameter mycelial plug from the actively growing edge of a 2-day-old culture was placed mycelial side down on one-half of the leaf. A reference isolate (ATCC MYA-4521) obtained from pea was inoculated on the other half of the leaf and incubated at room temperature (23 to $25^{\circ} \mathrm{C}$ ) with a 12 -h photoperiod, as described by Sexton et al. (50). Lesion size was captured with a digital camera $24 \mathrm{~h}$ after inoculation and lesion area was measured with the digital image analysis software Assess 2.0 (American Phytopathological Society, St. Paul, MN). Lesion area and its difference in comparison with the reference isolate were referred to as absolute lesion area and relative lesion area, respectively. Four replicate leaves per isolate were used and the experiment was performed twice.

Statistical analysis of phenotypic data. Statistical analyses were performed using SAS ver. 9.1 (SAS Institute, Cary, NC) and
Minitab 16 Statistical Software (Minitab, Inc., State College, PA). In analyzing the phenotypic data, reproducibility of each experiment was initially checked by comparing the repeated two trials. Significant difference between the first and second trials of each phenotypic trait was tested using PROC MIXED procedure in SAS, using trials as the random effect. If there was no significant difference between the repeated experiments, data were pooled for further analyses. On the other hand, if significant differences between trials were detected, data in the two trials were analyzed and presented separately. Significance of differences between the populations at $P<0.05$ was tested using nested ANOVA. Isolates and populations were treated as random and fixed, respectively. A nonparametric Mann-Whitney $U$ test was used when violation of model assumptions was detected in the residual plots because data transformation did not improve the homogeneity of variance. Twenty-eight correlation analyses were performed between pairs of all eight phenotypic traits to assess the possible relationships among them. Principal component analysis, a multivariate method to reduce a large number of interrelated variables to retain the highest amount of variation present in the data set via a new set of variables known as principal components (PCs), was performed with eight phenotypic variables (sensitivity to three fungicides, total oxalic acid production, sclerotial dry weight, mycelial dry weight, and virulence on two canola cultivars). To determine whether population is a significant predictor for the PC scores, PROC GLM analysis was conducted on the PC scores using SAS software.

Heritability of the eight phenotypic traits in the two populations was estimated. Phenotypic variance of an organism can be partitioned into several components: genetic variance, dominance effect, epistasis (among loci interaction), and environmental variance (22). Dominance effect does not occur in haploid organisms (57) such as $S$. sclerotiorum and, if epistasis is assumed to be negligible, the phenotypic variance is caused by only environmental and genetic variances $(46,57)$. Therefore, the total variance $\left(V_{\mathrm{P}}\right)$ for $S$. sclerotiorum was partitioned using the modified equation of Falconer and Mackay (22), as $V_{\mathrm{P}}=V_{\mathrm{A}}+V_{\mathrm{E}}$, where, $V_{\mathrm{A}}$ is the additive genetic variance and $V_{\mathrm{E}}$ is the environmental variance. Environmental variance can be estimated using variance among replicates (57). Thus, genetic variance in each population can be estimated as the phenotypic variance minus environmental variance. The Chinese population displayed two distinct phenotypic groups in sensitivity to benomyl; therefore, $V_{\mathrm{A}}$ was estimated for sensitive and insensitive groups separately. The variances in quantitative traits were partitioned into among-replicates and within-population components using the PROC VARCOMP in SAS software. The environmental variance was obtained from the among-replicates variance component. Heritability of each trait in each population was estimated as $V_{\mathrm{A}} / V_{\mathrm{P}}$ accordingly (22).

\section{RESULTS}

Genotypic characterization. Microsatellite genotyping. All the isolates showed a single allele in every locus, indicating that they were homokaryotic. All eight microsatellite markers were polymorphic in the U.S. population but only seven were polymorphic in the Chinese population (locus 12-2 was monomorphic) (Table 2). There were, in total, 42 alleles of the eight loci among all the isolates, and 11 of the 42 alleles were in common between the two populations (Table 2). The individual allele frequencies and expected heterozygosities of individual loci varied between the two populations (Table 2), even though the populations did not differ in the mean number of alleles per locus and average expected heterozygosities (Table 3 ). The total number of alleles and the number of private alleles were higher in the U.S. population than in the Chinese population (Table 3 ). Interestingly, the Chinese population was genotypically richer than the U.S. population, as indicated by the number of multilocus haplotypes 


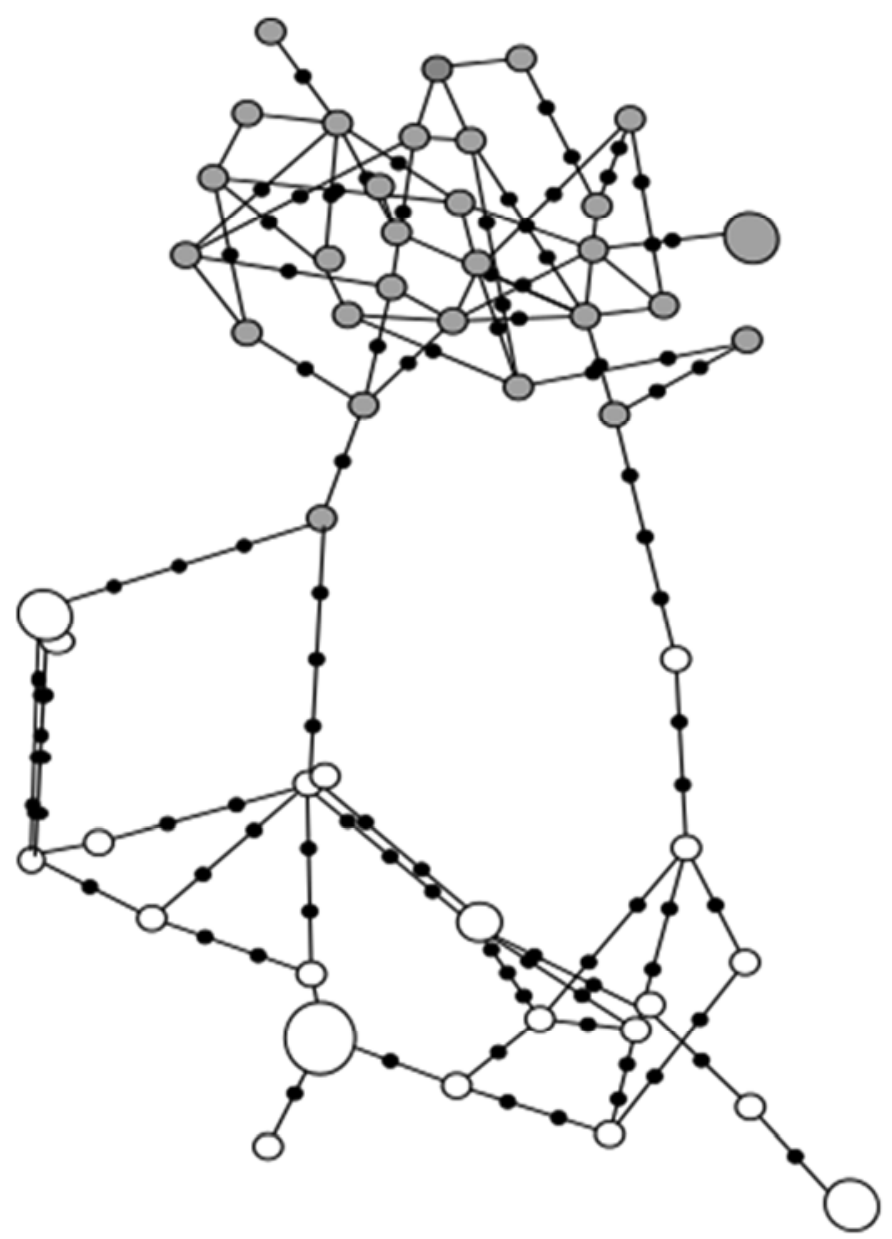

Fig. 1. Minimum spanning network of multilocus haplotypes based on eight microsatellite markers. Open circles represent haplotypes from the United States whereas closed circles represent haplotypes from China, and the size of a circle is proportionate to the frequency of the haplotype. The distance between nodes are proportionate to the genetic distance based on the stepwise mutation model, and black dots represent missing haplotypes. tation at the 368th position, which was identified as the type IV sequence (Fig. 3). The four types of sequences were deposited in the GenBank under the accession numbers JX181759, JX181760, JX181761, and JX181762. Specimens (sclerotia) of these four isolates were deposited in the Washington State University Plant Pathology Herbarium and assigned accession numbers WSP72219, WSP-72220, WSP-72218, and WSP-72217, respectively (Table 1).

Phenotypic characterization. Fungicide sensitivity. Sensitivity of the isolates to the three fungicides measured as percent inhibition of mycelial growth was shown in Figure 4. Significant differences among isolates within populations were observed $(P<$ 0.001 ) for all three fungicides. For benomyl sensitivity, two distinct groups of phenotypes were found in the Chinese population. The isolates that displayed $\leq 20 \%$ growth inhibition were considered as putatively resistant or insensitive isolates (Fig. 4A), and these 15 isolates had the type II sequence with a nonsynonymous transversion mutation in the $\beta$-tubulin gene (Fig. 3). The insensitive and sensitive phenotypic groups were analyzed separately due to violation of model assumption in the Chinese population. On average, the Chinese population displayed lower percent inhibition compared with the U.S. population for benomyl and iprodione (Fig. 4A and B; Table 4). Significant population differentiation $(P<0.001)$ was observed for the percent inhibition with benomyl and iprodione (Fig. 4C; Table 4). However, there was no significant difference in percent inhibition for fluazinam between the two populations $(P=0.49)$ (Table 4$)$.

Oxalic acid production and growth rate. Oxalate production was expressed as total oxalate produced and oxalate per unit mycelial dry weight (Table 4). An interval plot of the milligrams of oxalate produced per milligram of mycelial dry weight is shown in Figure 5A. Significant differences among isolates were detected $(P=0.02)$. Significant population differentiation was observed for the total oxalate production, oxalate per milligram of mycelial dry weight, and growth rate (mycelial dry weight) $(P<$ 0.05 ) (Table 4). On average, the Chinese isolates produced higher levels of oxalate compared with the U.S. isolates (Table 4). Mean mycelial dry weight of the Chinese population was lower than that of the U.S. population (Table 4).

Colony color and sclerotial production. Among the 29 U.S. isolates, colonies of 4 isolates were white in color and 25 isolates

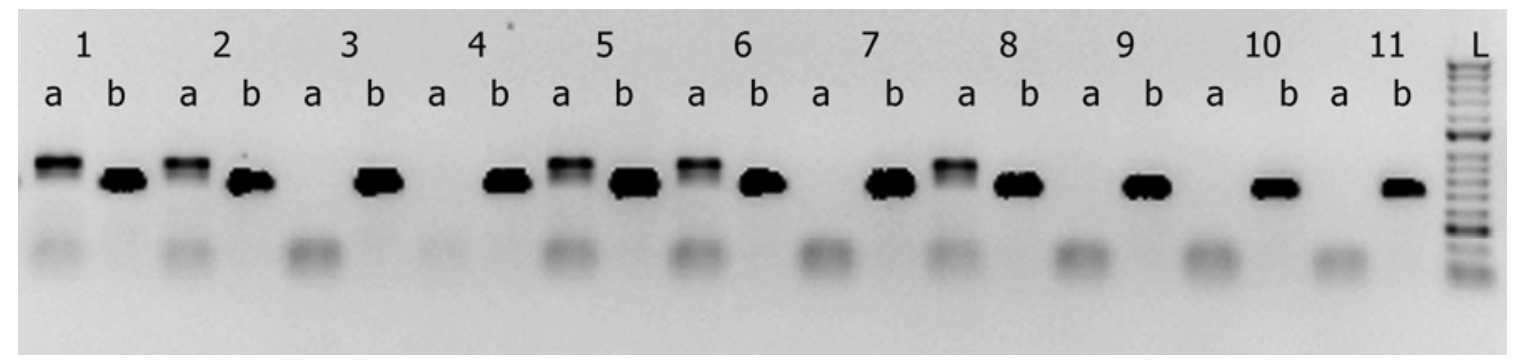

Fig. 2. Variation in polymerase chain reaction amplification of the mating type idiomorphs, MAT1-1 (a) and MAT1-2 (b) of 11 of Sclerotinia sclerotiorum isolates (lanes 1 to 11). Only MAT1-2 was amplified in lanes 3, 4, 7, 9, 10, and 11 whereas both MAT1-1 and MAT1-2 were amplified in lanes 1, 2, 5, 6, and 8. L denotes Hyper ladder II.

$\begin{aligned} & \text { Sequence } \\ & \text { type }\end{aligned}$
I
II
III

$\begin{array}{llll}0 & 1 & 3 & 5 \\ 0 & 9 & 6 & 6 \\ 1 & 3 & 8 & 0\end{array}$

8
7
4

$\begin{array}{cc}\text { \# of isolates } \\ \text { China } & \text { USA } \\ 0 & 24 \\ 15 & 0 \\ 13 & 5 \\ 2 & 0\end{array}$

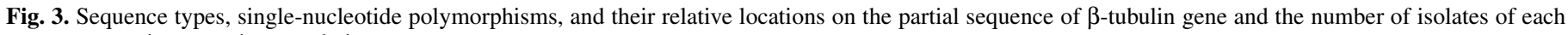
sequence type in respective populations. 
were beige color. However, 13 of the 30 Chinese isolates had unique black or darkly pigmented mycelia (Fig. 6). The dark colonies were much darker than we previously observed in a U.S. population of $S$. sclerotiorum from alfalfa (4). Seventeen isolates were beige color. White-colored mycelia were not observed among the Chinese isolates. Mean sclerotial weight for the U.S. population was higher than that of the Chinese population (Fig. 5B). Significant differences $(P<0.001)$ in sclerotial production among isolates as well as between populations were observed (Table 4).

Virulence assay. All of the isolates were pathogenic and were able to readily colonize leaves of the two canola cultivars in the detached-leaf assay. Mean absolute lesion areas of the isolates

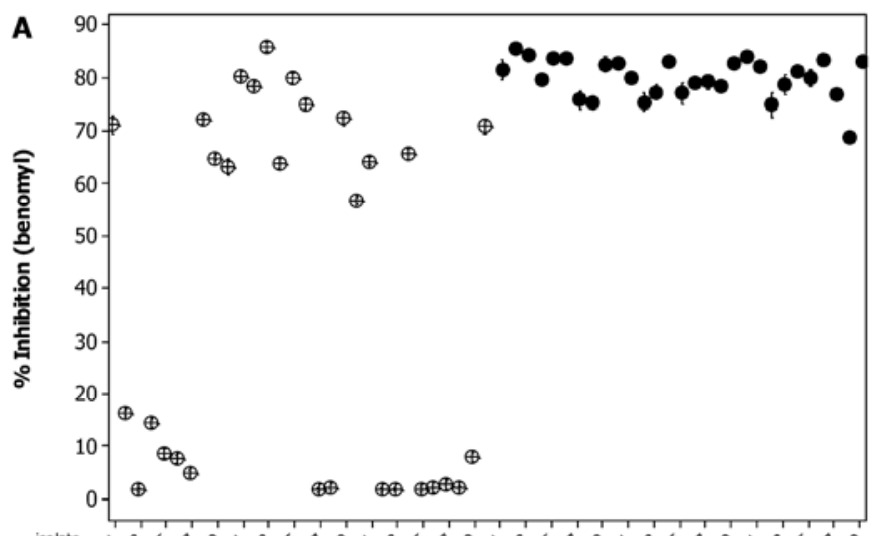

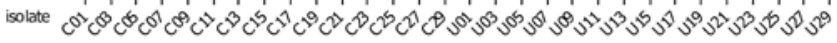
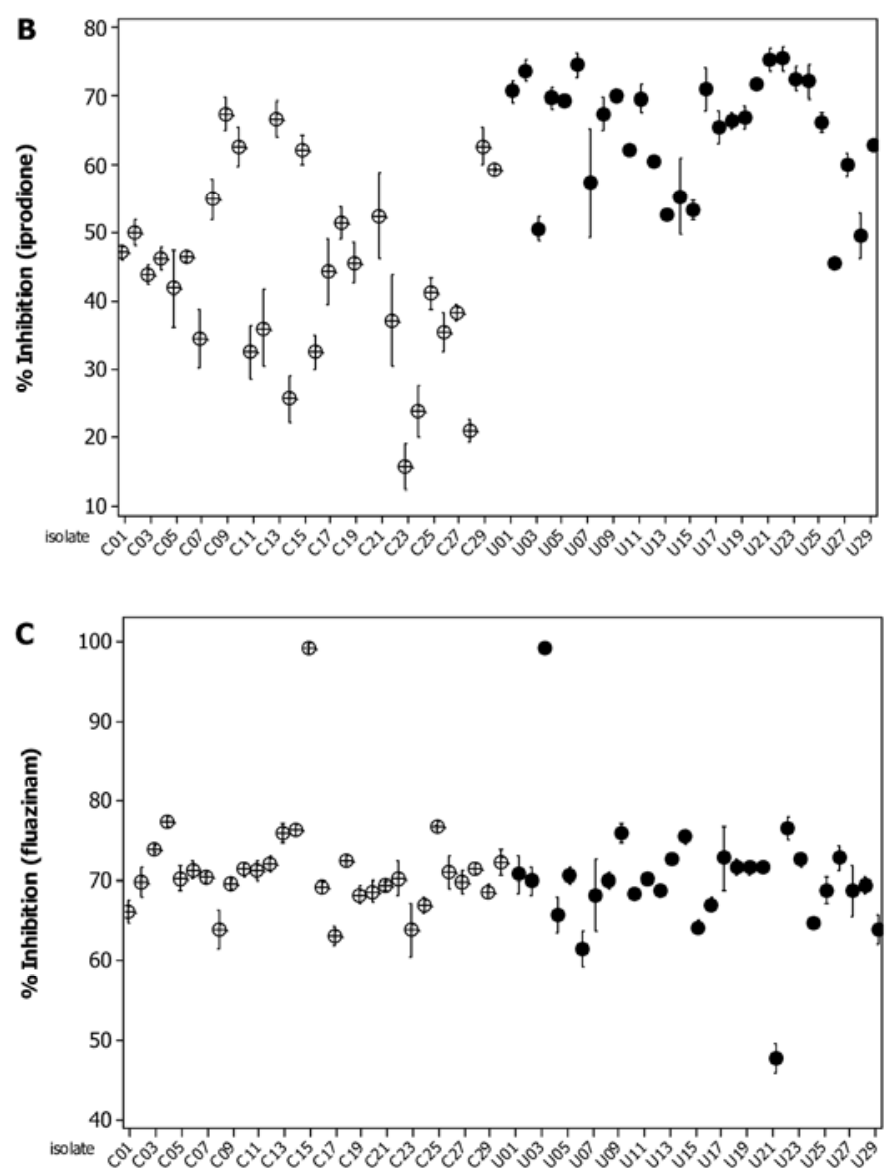

Fig. 4. Variation of percent inhibition of Sclerotinia sclerotiorum isolates from China (C01 to C30, open circles) and the United States (U01 to U29, closed circles) with three fungicides: $\mathbf{A}$, benomyl; $\mathbf{B}$, iprodione; and $\mathbf{C}$, fluazinam. Each point is the mean of six measurements and vertical bars represent one standard error of the mean. were $1.49 \pm 1.04$ and $2.76 \pm 1.07 \mathrm{~cm}^{2}$ on the moderately resistant (Hyola 357 Magnum) and susceptible (Dekalb 30-42) cultivars, respectively, and the difference was significant between the two cultivars $(P=0.03)$. Relative lesion area for each isolate was determined by the difference between the test isolate and the paired reference isolate. Pearson's correlation analysis between the repeated experiments found that stronger correlations exist for relative lesion area $(r=0.62, P=0.002$ for the susceptible cultivar; $r=0.5, P=0.005$ for the moderately resistant cultivar) than for the absolute lesion area $(r=0.27, P=0.08$ for the susceptible cultivar; $r=0.42, P=0.01$ for the moderately resistant culti-

A
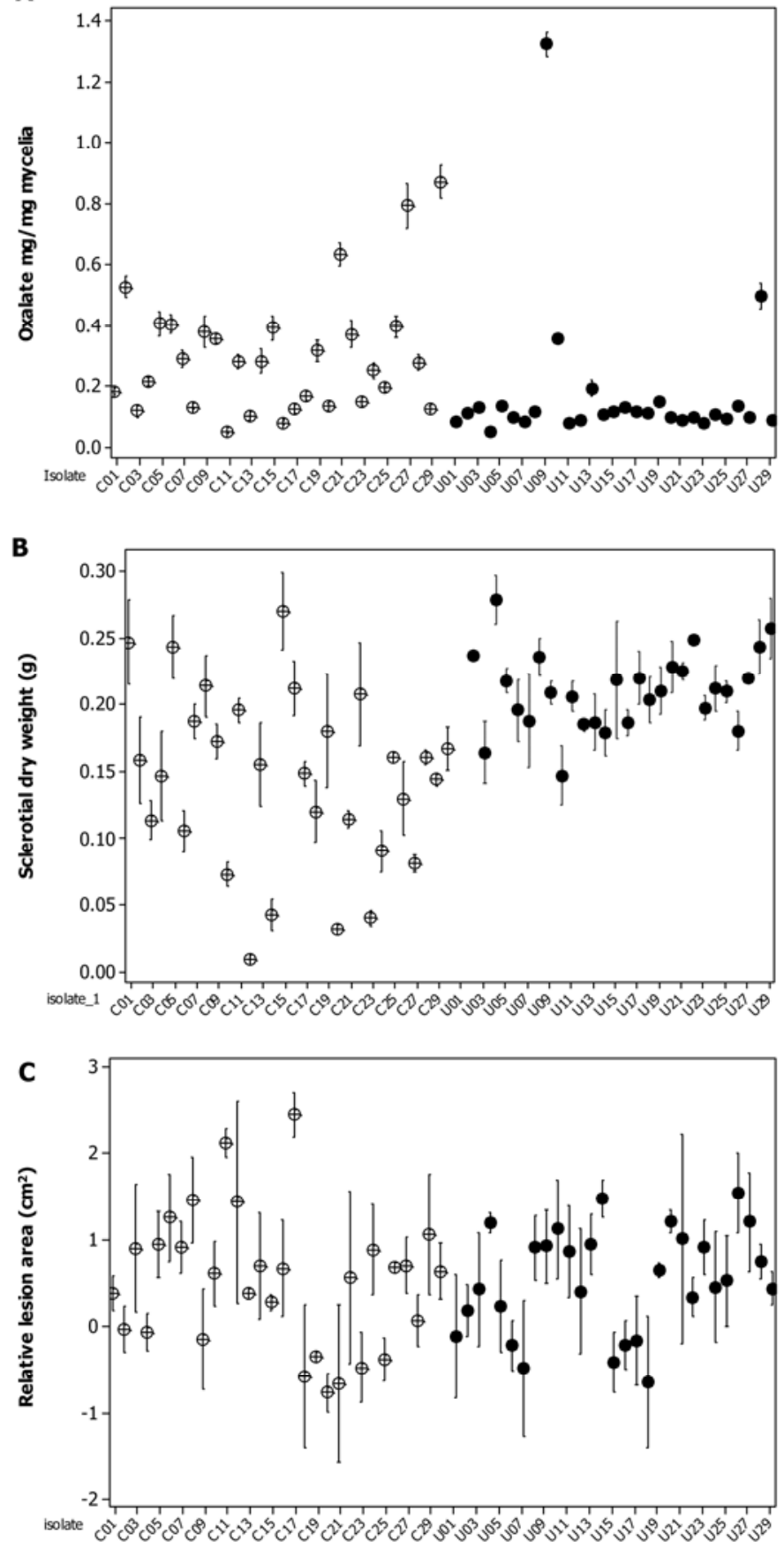

Fig. 5. Variation of Sclerotinia sclerotiorum isolates from China (C0 to C30, open circles) and the United States (U01 to U29, closed circles) for A, oxalic acid production; $\mathbf{B}$, sclerotial production; and $\mathbf{C}$, relative lesion area on canola cultivar 'Dekalb 30-42'. Each point is the mean of six measurements in A and $\mathrm{B}$ and of four measurements in C. Vertical bars represent one standard error of the mean. 
var). Therefore, the data of relative lesion area were used in the rest of the virulence analyses (Table 4). The first and second trials were analyzed separately because there was a significant difference between the trials. In both trials, significant differences among isolates for the virulence on both cultivars were found $(P=0.04$ and 0.03 for the susceptible and moderately resistant cultivars, respectively). However, no significant difference was detected $(P>0.05)$ between the two populations (Table 4; Fig. 5C).

Correlations and PC analysis among phenotypic traits. Of 28 Pearson's correlation analyses among eight phenotypic traits, 9 were significant at $P=0.05$ (Table 5). All the significant correlations were found among the five phenotypic traits: sensitivity to benomyl, sensitivity to iprodione, mycelial weight (growth rate), sclerotial production, and oxalate production. Among these five traits, only oxalate production was negatively correlated with the other four traits (Table 5). Even though oxalate production was not significantly correlated with virulence, correlation of oxalate production with virulence on the moderately resistant cultivar $(r=$ $0.23, P=0.14)$ was higher than with virulence on the susceptible cultivar $(r=-0.083, P=0.28)$ (Table 5). Results from PC analysis of the phenotypic traits revealed that $65 \%$ of the total variance among isolates was attributable to the first three PCs and nearly $77 \%$ was attributable to the first four components. PROC GLM analysis suggested that population is a significant predictor for the first PC. Sensitivity to benomyl and to iprodione, growth rate, sclerotial weight, and oxalate production contributed to the total variance.
Genetic variance and heritability. In general, genetic variances of phenotypic traits were higher in the Chinese population than in the U.S. population (Table 6). The genetic variances for percent inhibition of benomyl and iprodione, oxalate production, growth rate, and sclerotial weight in the Chinese population were severalfold higher than those of the U.S. population (Table 6). There was a high level of genetic variance for fluazinam sensitivity in the U.S. population. Despite the drastic differences in genetic variances for the traits studied, heritability of each trait was very similar between the two populations, suggesting that high levels of genetic variances found in the Chinese population were accompanied by high levels of environmental variances. Heritability values of virulence were lower in both populations than those of the other phenotypic traits (Table 6).

\section{DISCUSSION}

Sampling of S. sclerotiorum isolates from China and the United States enabled us to study genetic and phenotypic differentiation and diversity of geographically isolated populations from two continents; each population was associated with discrete environments and cultural practices. Even though the sample sizes are seemingly small, a preliminary study with larger sample sizes showed that most isolates were unique MCGs and unique microsatellite haplotypes, and it was felt that additional isolates would not be necessary and would make this extensive phenotyping unmanageable. Despite the wide range of genetic and phenotypic variation, all isolates were verified to be S. sclero-

TABLE 4. Comparison of population mean, standard deviation, and the significance of nonparametric Mann-Whitney U test of the phenotypic traits between the populations of Sclerotinia sclerotiorum form China and the United States

\begin{tabular}{lccc}
\hline Trait & China & United States & $P$ value \\
\hline Fungicide inhibition (\%) & & & $<.1 \pm 4.4$ \\
Benomyl & $42.4 \pm 29.5$ & $64.8 \pm 9.1$ & $<0.001$ \\
Iprodione & $45.0 \pm 13.9$ & $69.8 \pm 8.2$ & 0.49 \\
Fluazinam & $71.2 \pm 6.5$ & $13.1 \pm 3.5$ & 0.008 \\
Oxalate production & $15.9 \pm 4.3$ & $0.1 \pm 0.05$ & 0.03 \\
Total (mg) & $0.26 \pm 0.2$ & $125.5 \pm 32$ & 0.02 \\
mg/mg mycelial dry weight & $74 \pm 39$ & $0.2 \pm 0.04$ & $<0.001$ \\
Mycelial dry weight (mg) & $0.15 \pm 0.02$ & & 0.62 \\
Sclerotial dry weight (mg) & & $0.52 \pm 1.00$ & 0.57 \\
Virulence (relative lesion area) & $0.58 \pm 0.8$ & $0.55 \pm 0.85$ & 0.61 \\
Trial 1 & $0.46 \pm 0.82$ & $1.15 \pm 0.62$ & 0.79 \\
'Dekalb 30-42' & & $0.89 \pm 0.56$ & \\
'Hyola 357 Magnum' & $1.3 \pm 0.58$ & \\
$\quad$ 'Dekalb 30-42' & $0.98 \pm 0.66$ & & \\
'Hyola 357 Magnum' & & & \\
\hline
\end{tabular}
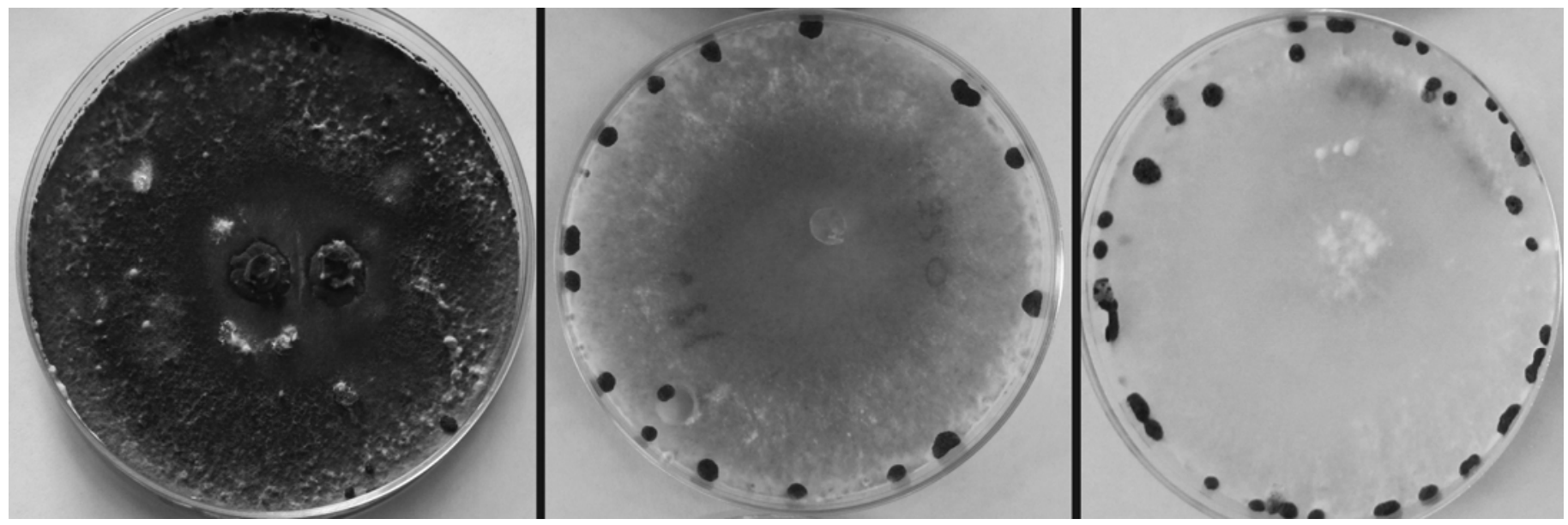

Fig. 6. Variation in mycelial pigmentation among isolates of Sclerotinia sclerotiorum (from left to right: black, beige, and white) on potato dextrose agar 3 weeks after inoculation. 
tiorum based on sclerotial size, $\beta$-tubulin gene sequence, and internal transcribed spacer sequences of selected isolates. The fact that all the microsatellite markers amplified expected allele sizes provides additional evidence that the isolates were $S$. sclerotiorum because these markers did not produce amplicons on two closely related species, $S$. minor and $S$. trifoliorum, in our previous study (43). Many traits were in common between the two populations: similar levels of mean number of alleles per locus, average expected heterozygosities, 11 shared alleles in seven microsatellite loci, equal distribution of inversion-minus and inversion-plus isolates, similar sensitivity to fungicide fluazinam, similar levels of virulence on two canola cultivars, and similar levels of heritability of all the measured quantitative traits.

A number of analyses have unequivocally shown that the Chinese and the U.S. populations were genetically differentiated: (i) no shared MCGs and multilocus haplotypes between the two populations; (ii) presence of a large number of private alleles in each population (Table 3); (iii) no shared alleles in the microsatellite locus 17-3 (Table 2); (iv) formation of two unambiguous Bayesian clustering groups in complete correspondence with the geographic origins, supported by the principle component analysis and MSN (Fig. 1); and (v) genetic variance between the two populations accounted for $>37 \%(P<0.001)$ of the total variance.

Significant population differentiation was detected not only in the molecular markers but also in phenotypic traits. The two populations were significantly differentiated for all of the studied phenotypic traits except virulence and fluazinam sensitivity. Chinese population was unique in many aspects: presence of isolates with darkly pigmented mycelia (Fig. 6; Table 1), reduced growth rate and sclerotia production, high levels of oxalic acid production (Table 4), and insensitivity to benomyl and to iprodione (Fig. 4). Small-scale farming practices with high crop diversity, environmental variations, and poor weed control in the
Chinese agricultural system may have had an impact on the observed differences.

Both populations showed signs of outcrossing, indicated by high recombination rates. The Chinese population had a higher recombination rate than did the U.S. population, as shown by the lack of significance in the $I_{A}$ and $r_{d}$ tests of both original and clone-corrected data sets of the Chinese population but only the clone-corrected dataset of the U.S. population (Table 3), more frequent reticulations in MSN (Fig. 1), and the discordance between MCGs and multilocus haplotypes. The hot and humid climate in Anhui province in China might have been conducive to frequent recombination in S. sclerotiorum. Huang (29) reported that sclerotia exposed to subfreezing temperatures often germinated myceliogenically. Similarly, frigid winter conditions in North Dakota might be more favorable for myceliogenic germination of sclerotia than the mild winter conditions in Anhui province in China, resulting in a relatively low level of recombination. Carbone and Kohn (9) reported the recombination in subtropical agricultural and temperate wild populations but not in the temperate agricultural populations. Atallah et al. (3) reported recombination among isolates collected from potato fields from the Columbia Basin in Washington, where mild winters and high crop diversity are present.

Recently, Chitrampalam et al. (10), while studying the variation of MAT loci of S. sclerotiorum, detected a 3.6-kb inversion in the mating type loci, and the inversion was widespread. The inversion truncates the MAT1-1-1 allele and the inversion happens each time it undergoes meiosis, giving 1:1 distribution of inversionminus and inversion-plus isolates. In this study, $\sim 60 \%$ of the isolates in both populations were inversion-plus isolates, falling within 1:1 distribution. Both inversion-plus and inversion-minus isolates are self-fertile (10). Thus, the significance of the inversion of the mating type loci on outcrossing is not clear.

TABLE 5. Pearson's correlations $(r)$ between phenotypic traits of Sclerotinia sclerotiorum isolates from China and the United States ${ }^{\mathrm{a}}$

\begin{tabular}{|c|c|c|c|c|c|c|c|c|}
\hline Phenotypic trait & Fluazinam & Benomyl & Iprodione & $\begin{array}{c}\text { Sclerotial } \\
\text { weight }\end{array}$ & $\begin{array}{l}\text { Mycelial } \\
\text { weight }\end{array}$ & $\begin{array}{c}\text { Total } \\
\text { oxalate }\end{array}$ & $\begin{array}{c}\text { Virulence } \\
\text { 'Dekalb 30-42' }\end{array}$ & $\begin{array}{c}\text { Virulence 'Hyola } \\
357 \text { Magnum' }\end{array}$ \\
\hline Fluazinam & 1.00 & & $\ldots$ & $\ldots$ & $\ldots$ & $\ldots$ & $\ldots$ & $\ldots$ \\
\hline Benomyl & 0.02 & 1.00 & $\ldots$ & $\ldots$ & $\ldots$ & $\ldots$ & $\ldots$ & $\ldots$ \\
\hline Iprodione & -0.04 & $0.62 * *$ & 1.00 & $\ldots$ & $\ldots$ & $\ldots$ & $\ldots$ & $\ldots$ \\
\hline Sclerotial weight & -0.01 & $0.33 * *$ & $0.58 * *$ & 1.00 & $\ldots$ & $\ldots$ & $\ldots$ & $\ldots$ \\
\hline Mycelial weight & -0.18 & $0.57 * *$ & $0.49 * *$ & $0.34 *$ & 1.00 & $\ldots$ & $\ldots$ & $\ldots$ \\
\hline Total oxalate & -0.01 & $-0.32 *$ & -0.26 & $-0.47 * *$ & $-0.36^{*}$ & 1.00 & $\ldots$ & $\ldots$ \\
\hline Virulence 'Dekalb 30-42' & 0.02 & 0.049 & -0.17 & -0.02 & -0.13 & -0.083 & 1.00 & $\ldots$ \\
\hline Virulence 'Hyola 357 Magnum' & 0.13 & -0.002 & -0.12 & -0.17 & -0.22 & 0.23 & 0.13 & 1.00 \\
\hline
\end{tabular}

a Asterisks: * and ** indicate $P<0.05$ and 0.001 , respectively.

TABLE 6. Comparison of Sclerotinia sclerotiorum populations from China and the United States for genetic variance and heritability of phenotypic traits

\begin{tabular}{|c|c|c|c|c|}
\hline \multirow[b]{2}{*}{ Trait } & \multicolumn{2}{|c|}{ Genetic variance } & \multicolumn{2}{|c|}{ Heritability } \\
\hline & China & United States & China & United States \\
\hline \multicolumn{5}{|l|}{ Benomyl $^{\mathrm{a}}$} \\
\hline Sensitive & 61.52 & 14.58 & 0.97 & 0.98 \\
\hline Iprodione & 155.8 & 66.5 & 0.70 & 0.78 \\
\hline Fluazinam & 38.33 & 59.325 & 0.87 & 0.86 \\
\hline Total oxalate (mg) & 23.68 & 12.17 & 0.93 & 0.91 \\
\hline \multicolumn{5}{|l|}{ Virulence trial 1} \\
\hline 'Dekalb 30-42' & 0.19 & 0.2 & 0.12 & 0.19 \\
\hline 'Hyola 357 Magnum' & 0.21 & 0.4 & 0.21 & 0.31 \\
\hline \multicolumn{5}{|l|}{ Virulence trial 2} \\
\hline 'Dekalb 30-42' & 0.02 & 0.08 & 0.079 & 0.03 \\
\hline 'Hyola 357 Magnum' & 0.31 & 0.27 & 0.21 & 0.15 \\
\hline
\end{tabular}

a Due to bimodal distributions in sensitivity to benomyl, the Chinese population was divided into sensitive and insensitive for the calculation of additive genetic variance and heritability. 
Chitrampalam et al. (10) suggested that similar inversion mechanisms could be operative in $S$. trifoliorum and other ascomycetes. $S$. trifoliorum possesses ascospore dimorphism; half (large-sized ascospores) of the ascospore progenies were homothallic and the other half (small-sized ascospores) were heterothallic (56). Ekins et al. (15) reported a rare example of ascospore dimorphism in $S$. sclerotiorum, reminiscent of the situation in S. trifoliorum. The frequency of meiosis (carpogenic germination) of $S$. sclerotiorum is influenced by the environment (29). The more frequent the meiosis, the more opportunities for inversion and more chances of imprecise inversions, creating errors in the mating type idiomorphs likely resulting in isolates incapable of being homothallic. Other possible mechanisms of recombination via outcrossing have been discussed by Atallah et al. (3) and Sexton et al. (51).

Correlation analyses showed that five phenotypic traits were correlated: sensitivity to benomyl, sensitivity to iprodione, sclerotia production, growth rate, and oxalate production. The biological meanings of these correlations are not all clear. The significant positive correlation between benomyl and iprodione sensitivity (Table 5) suggests the potential of developing cross resistance. Benomyl belongs to the benzimidazole group, which inhibits $\beta$-tubulin assembly in mitosis, whereas iprodione belongs to the dicarboximide group, which affects osmotic signal transduction (http://www.frac.info/frac/index.htm). During the 1990s, benomyl application was a common practice for white mold control in China. Resistance to benomyl was detected in 1996 (35) and benomyl application has ceased since then. Even after a decade without selection pressure, 15 isolates $(50 \%)$ of the Chinese population were still resistant to benomyl, suggesting that resistance to benomyl has no or minimal fitness cost. Resistance to benomyl was not detected in the U.S. population or among the other 300 isolates collected from various crops in the U.S. Pacific Northwest (unpublished data). However, benomyl resistance in $S$. sclerotiorum has been detected in Canada (24) and resistance to benomyl and iprodione has been detected in $S$. minor in the United States $(8,30)$. Even though benomyl is no longer in commercial use, thiophanate and thiophanate methyl, which belong to the same fungicide group as benomyl, are recommended for managing Sclerotinia diseases in the United States (7). Iprodione is recommended for control of S. sclerotiorum white mold on lettuce in the United States and on canola in China (37). Therefore, the possibility of development of cross resistance should be taken into consideration in choosing fungicides for managing Sclerotinia white mold. Iprodione sensitivity was also positively correlated with sclerotial production and growth rate (Table 5). An earlier report showed that laboratory-induced iprodione-resistant mutants produced darkly pigmented mycelia with reduced sclerotial production, and were associated with two point mutations on a growth-rate-related $o s-1$ gene (37). Here, we report such a relationship of iprodione sensitivity with low sclerotial production and growth rate in natural populations, although the genetic changes in the insensitive isolates remain to be determined. A significant negative correlation between oxalate production and the other traits suggests that excessive oxalate production is detrimental for growth and sclerotial formation in saprophytic growth but is beneficial under stress conditions such as fungicide pressure and, possibly, under host resistance in resistant or moderately resistant cultivars.

The different susceptibilities between the two canola cultivars is clearly shown by the significant difference $(P=0.03)$ in average lesion sizes of all isolates. Yet the two populations showed no difference in causing leaf colonization on either of the two cultivars, and the values of virulence on both cultivars were not correlated with any of the other measured quantitative traits. However, the virulence on the moderately resistant (but not the susceptible) cultivar was moderately correlated with oxalate production and mycelial growth rate $(P=0.14$ and 0.12 , respectively). These suggest that oxalate production is more important in causing disease on resistant cultivars than on susceptible cultivars. Thus, different cultivars of the same host species used in virulence assays may show different relationships between virulence and other traits such as oxalate production. Virulence of S. sclerotiorum has been a subject of many studies, and uniformity $(3,5,11,41$, $47,50)$ as well as significant difference among isolates and among geographic locations $(34,36,44)$ has been reported. Sexton et al. (50) reported a lack of significant difference in virulence among isolates from different canola fields. However, conflicting reports are available reporting significant correlations as well as lack of correlations among phenotypic traits and virulence $(17,31,36,41)$.

The Chinese population had greater (several-fold higher) genetic variance for most of the traits than the U.S. population but the heritability values were very comparable or similar between the two populations and were relatively high for all the traits, except for virulence (Table 6). The high values of heritability indicate that variation observed in these traits is largely due to a genetic component. Low heritability in virulence suggests two things. First, it is likely that virulence has been under strong selection in both populations, because an erosion of heritability is expected under selection $\left(R=h^{2} S\right)$. Second, the low heritability values for virulence suggest that the variation in virulence is largely influenced by the environmental conditions, explaining why virulence data of two repeated trails were not correlated. This further points out the necessity of closely controlling the environment in conducting virulence assays. Also, the comparable heritability values between two such differentiated populations suggest that heritability of a given trait is stable for S. sclerotiorum.

This research has several practical and theoretical implications. First, this is the first study that characterizes most of the important phenotypic traits relevant to agricultural practices on the same set of isolates and reports a great level of genetic and phenotypic differentiation. High levels of genetic diversity and a wide range of phenotypic variation were found among the isolates. Second, high heritability values were observed for most of the phenotypic traits. A trait with high heritability is more likely to respond to selection than a trait with low heritability and, therefore, the heritability information of the pathogen should be considered in managing the disease, such as in selecting fungicides. Third, pathogen virulence has a major environmental component relative to other phenotypic traits and, therefore, when screening breeding materials for resistance, controlled environmental conditions should be adapted for more consistent results. To manage the disease, cultural practices, including environmental management, are important, considering the paucity of available crop cultivars resistant to this pathogen. Fourth, cross resistance may develop in $S$. sclerotiorum for fungicides (especially to benzimidazole and dicarboximide fungicides) and care should be exercised in fungicide selection. Fifth, a single discriminatory dose for fast benomyl resistance screening was found possible and can be used at locations where molecular facilities are not available. Finally, the distinct genetic and phenotypic differences between the two populations support the importance of restrictions on pathogen movement. Currently, quarantine restrictions are applied on movement of pathogens by species names without regard to genotypes. New and novel genotypes could be imported, potentially generating novel and betteradapted genotypes via recombination.

\section{ACKNOWLEDGMENTS}

The project was funded, in part, by the United States Department of Agriculture-Agricultural Research Service (USDA-ARS) National Sclerotinia Initiative. We thank F. Dugan of USDA-ARS and D. Johnson of Washington States University for critically reviewing the manuscript, N. Dasgupta of Washington State University for consultation on statistical analysis, D. See of USDA-ARS for providing the genotyping facility, and 
K. V Subbarao of the University of California-Davis for providing prepublication information on invasion of MAT loci.

\section{LITERATURE CITED}

1. Agapow, P.-M., and Burt, A. 2001. Indices of multilocus linkage disequilibrium. Mol. Ecol. Notes 1:101-102.

2. Anderson, J. B., and Kohn, L. M. 1995. Clonality in soilborne, plantpathogenic fungi. Annu. Rev. Phytopathol. 33:369-391.

3. Atallah, Z. K., Larget, B., Chen, X., and Johnson, D. A. 2004. High genetic diversity, phenotypic uniformity, and evidence of outcrossing in Sclerotinia sclerotiorum in the Columbia Basin of Washington State. Phytopathology 94:737-742.

4. Attanayake, R. N., Porter, L., Johnson, D. A., and Chen, W. 2012. Genetic and phenotypic diversity and random association of DNA markers of isolates of the fungal plant pathogen Sclerotinia sclerotiorum from soil on a fine geographic scale. Soil Biol. Biochem. 55:28-36.

5. Auclair, J., Boland, G. J., Kohn, L. M., and Rajcan, I. 2004. Genetic interactions between Glycine max and Sclerotinia sclerotiorum using a straw inoculation method. Plant Dis. 88:891-895.

6. Boland, G. J., and Hall, R. 1994. Index of plant hosts of Sclerotinia sclerotiorum. Can. J. Plant Pathol. 16:93-108.

7. Bradley, C. A., Lamey, H. A., Endres, G. J., Henson, R. A., Hanson, B. K., McKay, K. R., Halvorson, M., LeGare, D. G., and Porter, P. M. 2006. Efficacy of fungicides for control of Sclerotinia stem rot of canola. Plant Dis. 90:1129-1134.

8. Brenneman, T. B., Phipps, P. M., and Stipes, R. J. 1987. Sclerotinia blight of peanut: relationship between in vitro resistance and field efficacy on dicarboximide fungicides. Phytopathology 77:1028-1032.

9. Carbone, I., and Kohn, L. M. 2001. A microbial population-species interface: Nested cladistic and coalescent inference with multilocus data. Mol. Ecol. 10:947-964.

10. Chitrampalam, P., Inderbitzin, P., Maruthachalam, K., Wu, B. M., and Subbarao, K. V. The Sclerotinia sclerotiorum mating type locus (MAT) contains a $3.6-\mathrm{kb}$ region that is inverted in every generation. PLoS One. 8(2):e56895. doi:10.1371/journal.pone.0056895

11. Durman, S. B., Menendez, A. B., and Godeas, A. M. 2003. Mycelial compatibility groups in Buenos Aires field populations of Sclerotinia sclerotiorum (Sclerotiniaceae). Aust. J. Bot. 51:421-427.

12. Durman, S. B., Menendez, A. B., and Godeas, A. M. 2005. Variation in oxalic acid production and mycelial compatibility within field populations of Sclerotinia sclerotiorum. Soil Biol. Biochem. 37:2180-2184.

13. Dutton, M. V., and Evans, C. S. 1996. Oxalate production by fungi: Its role in pathogenicity and ecology in the soil environment. Can. J. Microbiol. 42:881-895.

14. Earl, D. A., and vonHoldt, B. M. 2011. STRUCTURE HARVESTER: A website and program for visualizing STRUCTURE output and implementing the Evanno method. Conserv. Genet. Resour. 4:359-361.

15. Ekins, M., Aitken, E. A., and Coulter, K. C. 2006. Homothallism in Sclerotinia minor. Mycol. Res. 110:1193-1199.

16. Ekins, M. G., Hayden, H. L., Aitken, E. A. B., and Goulter, K. C. 2011. Population structure of Sclerotinia sclerotiorum on sunflower in Australia. Australas. Plant Pathol. 40:99-108.

17. Errampalli, D., and Kohn, L. M. 1995. Comparison of pectic zymograms produced by different clones of Sclerotinia sclerotiorum in culture. Phytopathology 85:292-298.

18. Evanno, G., Regnaut, S., and Goudet, J. 2005. Detecting the number of clusters of individuals using the software STRUCTURE: A simulation study. Mol. Ecol. 14:2611-2620.

19. Excoffier, L., and Lischer, H. E. 2010. Arlequin suite ver. 3.5: A new series of programs to perform population genetics analyses under Linux and Windows. Mol. Ecol. Resour. 10:564-567.

20. Excoffier, L., and Smouse, P. E. 1994. Using allele frequencies and geographic subdivision to reconstruct gene trees within a species: molecular variance parsimony. Genetics 136:343-359.

21. Excoffier, L., Smouse, P. E., and Quattro, J. M. 1992. Analysis of molecular variance inferred from metric distances among DNA haplotypes: Application to human mitochondrial DNA restriction data. Genetics 131:479-491.

22. Falconer, D. S., and Mackay, T. F. C. 1996. Introduction to Quantitative Genetics. Longman Group Ltd., Harlow, Essex, England.

23. Gomes, E. V., do Nascimento, L. B., de Freitas, M. A., Nasser, L. C. B., and Petrofeza, S. 2011. Microsatellite markers reveal genetic variation within Sclerotinia sclerotiorum populations in irrigated dry bean crops in Brazil. J. Phytopathol. 159:94-99.

24. Gossen, B. D., Rimmer, S. R., and Holley, J. D. 2001. First report of resistance to benomyl fungicide in Sclerotinia sclerotiorum. Plant Dis. 85:1206.

25. Grogan, R. G. 1979. Sclerotinia species: Summery and comments on needed research. Phytopathology 69:908-910.

26. Hambleton, S., Walker, C., and Kohn, L. M. 2002. Clonal lineages of Sclerotinia sclerotiorum previously known from other crops predominate in 1999-2000 samples from Ontario and Quebec soybean. Can. J. Plant Pathol. 24:309-315.

27. Hegedus, D. D., and Rimmer, S. R. 2005. Sclerotinia sclerotiorum: when "to be or not to be" a pathogen? FEMS Microbiol. Lett. 251:177-184.

28. Hemmati, R., Javan-Nikkhah, M., and Linde, C. C. 2009. Population genetic structure of Sclerotinia sclerotiorum on canola in Iran. Eur. J. Plant Pathol. 125:617-628.

29. Huang, H. C. 1991. Induction of myceliogenic germination of sclerotia of Sclerotinia sclerotiorum by exposure to sub-freezing temperatures. Plant Pathol. 40:621-625.

30. Hubbard, J. C., Subbarao, K. V., and Koike, S. T. 1997. Development and significance of dicarboximide resistance in Sclerotinia minor isolates from commercial lettuce fields in California. Plant Dis. 81:148-153.

31. Irani, H., Heydari, A., Javan-Nikkhah, M., and İbrahimov, A. S. 2011. Pathogenicity variation and mycelial compatibility groups in Sclerotinia sclerotiorum. J. Plant Prot. Res. 51:329-351.

32. Koenraadt, H., Somerville, S. C., and Jones, A. L. 1992. Characterization of mutations in the beta-tubulin gene of benomyl-resistant field strains of Venturia inaequalis and other plant pathogenic fungi. Mol. Plant Pathol. 82:1348-1354

33. Kohli, Y., Brunner, L. J., Yoell, H., Milgroom, M. G., Anderson, J. B., Morrall, R. A. A., and Kohn, L. M. 1995. Clonal dispersal and spatial mixing in populations of the plant pathogenic fungus, Sclerotinia sclerotiorum. Mol. Ecol. 4:69-77.

34. Kull, L. S., Pedersen, W. L., Palmquist, D., and Hartman, G. L. 2004. Mycelial compatibility grouping and aggressiveness of Sclerotinia sclerotiorum. Plant Dis. 88:325-332.

35. Li, H., Zhou, M., and Lu, Y. J. 2002. Using polymerase chain reaction for detection of carbendazim resistance in Sclerotinia sclerotiorum. Mycosystema 21:370-374.

36. Li, Z., Zhang, M., Wang, Y., Li, R., and Fernando, W. G. D. 2008 Mycelial compatibility group and pathogenicity variation of Sclerotinia sclerotiorum populations in sunflower from China, Canada and England. Plant Pathol. J. 7:131-139.

37. Liu, X., Yin, Y., Yan, L., Michailides, T. J., and Ma, Z. 2009. Sensitivity to iprodione and boscalid of Sclerotinia sclerotiorum isolates collected from rapeseed in China. Pestic. Biochem. Physiol. 95:106-112.

38. Malvárez, G., Carbone, I., Grünwald, N. J., Subbarao, K. V., Schafer, M., and Kohn, L. M. 2007. New populations of Sclerotinia sclerotiorum from lettuce in California, and peas and lentils in Washington. Phytopathology 97:470-483.

39. McDonald, B. A., and Linde, C. 2002. Pathogen population genetics, evolutionary potential, and durable resistance. Annu. Rev. Phytopathol. 40:349-379.

40. Mert-Turk, F., Ipek, M., Mermer, D., and Nicholson, P. 2007. Microsatellite and morphological markers reveal genetic variation within a population of Sclerotinia sclerotiorum from oilseed rape in the Canakkale Province of Turkey. J. Phytopathol. 155:182-187.

41. Morrall, R. A. A., Duczek, L. J., and Sheard, J. W. 1972. Variations and correlations within and between morphology, pathogenicity, and pectolytic enzyme activity in Sclerotinia from Saskatchewan. Can. J. Bot. 50:767-786

42. Nei, M. 1973. Analysis of gene diversity in subdivided populations. Proc. Natl. Acad. Sci. USA 70:3321-3323.

43. Njambere, E. N., Vandemark, G., and Chen, W. 2010. Development and characterization of microsatellite markers of the fungal plant pathogen Sclerotinia trifoliorum. Genome 53:494-500.

44. Otto-Hanson, L., Steadman, J. R., Higgins, R., and Eskridge, K. M. 2011. Variation in Sclerotinia sclerotiorum bean isolates from multisite resistance screening locations. Plant Dis. 95:1370-1377.

45. Peakall, R. O. D., and Smouse, P. E. 2006. GenAlEx 6: Genetic analysis in Excel. Population genetic software for teaching and research. Mol. Ecol. Notes 6:288-295.

46. Peever, T. L., and Milgroom, M. G. 1995. Genetic correlations in resistance to morpholine and piperidine fungicides in Pyrenophora teres populations. Eur. J. Plant Pathol. 101:93-99.

47. Pratt, R. G., and Rowe, D. E. 1995. Comparative pathogenicity of isolates of Sclerotinia trifoliorum and S. sclerotiorum on alfalfa cultivars. Plant Dis. 79:474-477.

48. Pritchard, J. K., Stephens, M., and Donnelly, P. 2000. Inference of population structure using multilocus genotype data. Genetics 155:945-959.

49. Schafer, M. R., and Kohn, L. M. 2006. An optimized method for mycelial compatibility testing in Sclerotinia sclerotiorum. Mycologia 98:593-597.

50. Sexton, A. C., and Howlett, B. J. 2004. Microsatellite markers reveal genetic differentiation among populations of Sclerotinia sclerotiorum from Australian canola fields. Curr. Genet. 46:357-365. 
51. Sexton, A. C., Whitten, A. R., and Howlett, B. J. 2006. Population structure of Sclerotinia sclerotiorum in an Australian canola field at flowering and stem-infection stages of the disease cycle. Genome 49:1408-1415.

52. Sirjusingh, C., and Kohn, L. M. 2001. Characterization of microsatellites in the fungal plant pathogen, Sclerotinia sclerotiorum. Mol. Ecol. Notes 1:267-269.

53. Slatkin, M. 1995. A measure of population subdivision based on microsatellite allele frequencies. Genetics 139:457-462.

54. Stoddart, J. A., and Taylor, J. F. 1988. Genotypic diversity: estimation and prediction in samples. Genetics 118:705-711.

55. Teacher, A. G. F., and Griffiths, D. J. 2011. HapStar: automated haplotype network layout and visualization. Mol. Ecol. Resour. 11:151-153.

56. Uhm, J. Y., and Fujii, H. 1983. Heterothallism and mating type mutation in Sclerotinia trifoliorum. Phytopathology 73:569-572.

57. Zhan, J., Linde, C. C., Jurgens, T., Merz, U., Steinebrunner, F., and McDonald, B. A. 2005. Variation for neutral markers is correlated with variation for quantitative traits in the plant pathogenic fungus Mycosphaerella graminicola. Mol. Ecol. 14:2683-2693. 